\title{
Endoscopic retrieval of a metal stent embedded in the colon wall
}

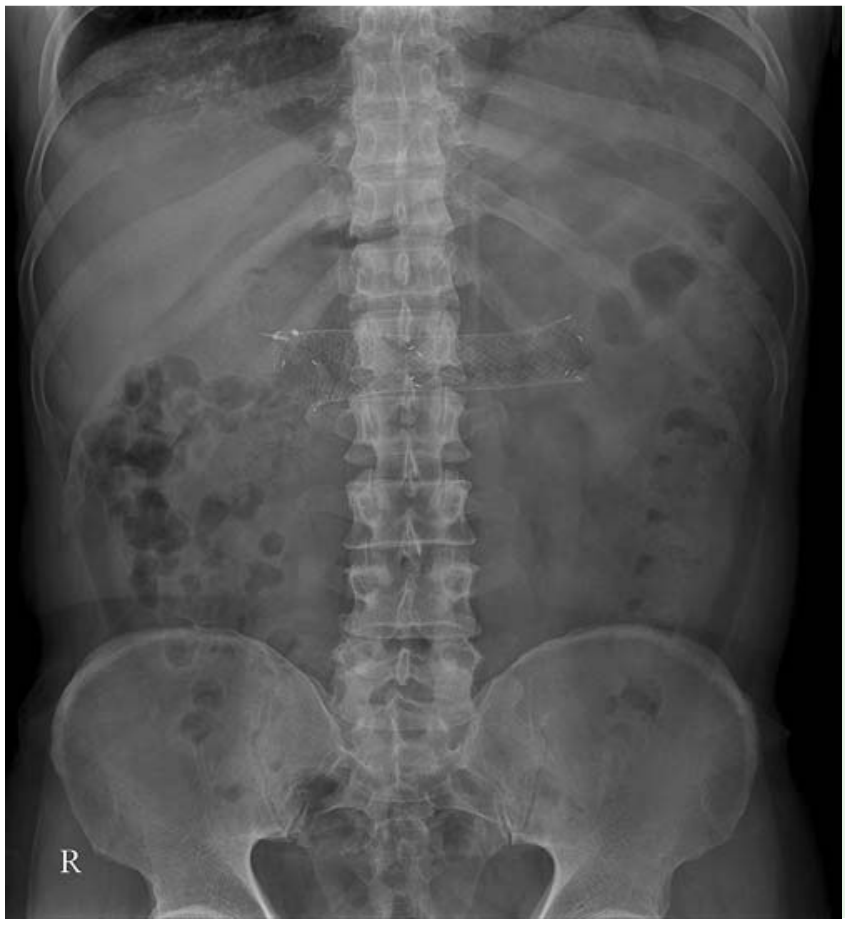

Fig. 1 Simple abdominal radiograph showing that the metal stent had migrated from the ascending colon to the transverse colon.

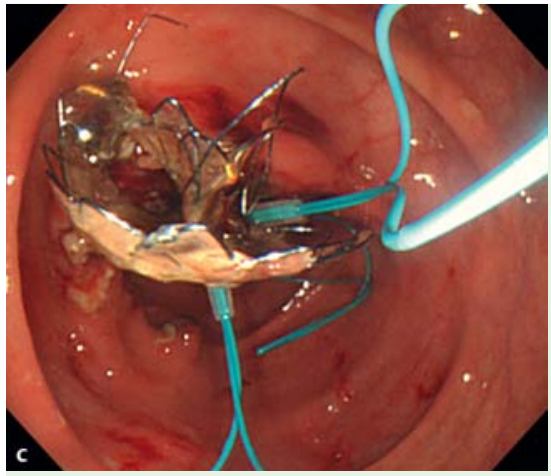

Fig. 2 a Colonoscopy revealed that the migrated uncovered stent was impacted in the mid transverse colon due to the formation of granulation tissue and hyperemic mucosal hyperplasia. The metal stent was embedded within the bowel wall at multifocal points over nearly the whole length of the stent. b Argon plasma coagulation (APC) was performed repeatedly on the remain-

Migration is one of the major complications after inserting a self-expandable metal stent (SEMS) into the colon [1-3]. We report a case of a migrated SEMS from the ascending colon that had been impacted into the wall of the transverse colon. A patient diagnosed with cancer of the ascending colon with stenosis was admitted. The length of the stenotic colon can-

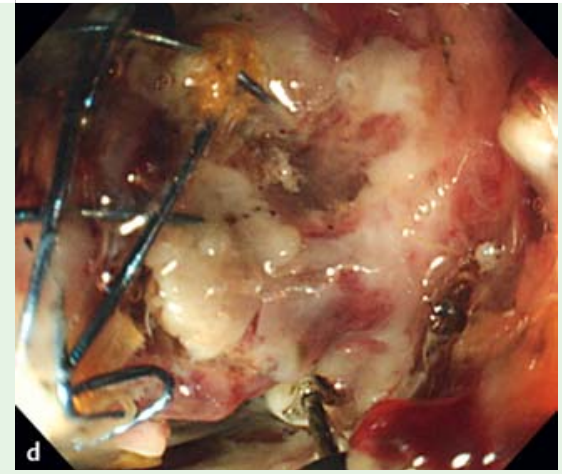

ing ingrown tissue. After ensuring sufficient ablation and necrosis of the ingrown tissue, APC was applied to the more proximal part of the ingrown tissue. c After detachment of a significant portion of the stent from the bowel wall, a detachable snare was used to compress the distal part of the stent in order to avoid colonic mucosal injury which can occur during retrieval due to the stent

cer lesion was about $5 \mathrm{~cm}$, and an uncovered SEMS was inserted (Hanaro Stent, uncovered; $100 \mathrm{~mm}$ in length, $24 \mathrm{~mm}$ in diameter; MITech, Seoul, Korea). The patient was treated with oxaliplatin, 5fluorouracil, and leucovorin (FOLFOX) chemotherapy.

After 6 weeks with the stent inserted, the patient complained of severe colicky ab-
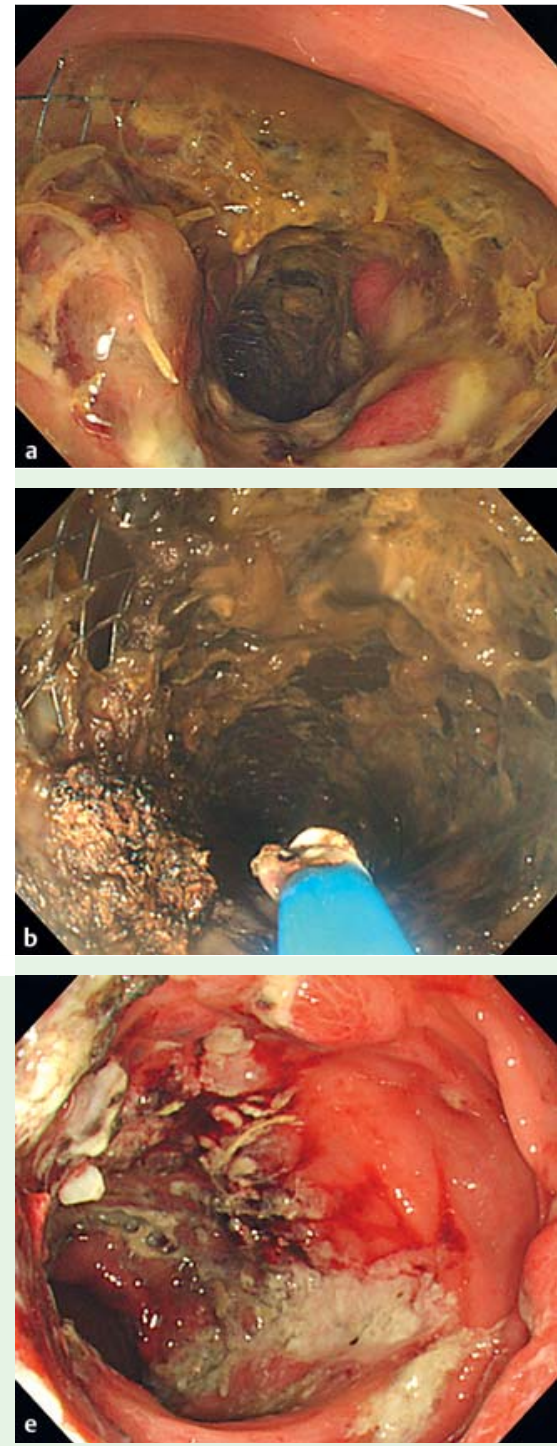

margin. $\mathbf{d}$ Dissection of the stent from the tightly attached tissue was carefully performed using the insulation-tipped diathermic knife-2 set in drycut mode - effect 4. $\mathbf{e}$ The process was performed successfully to remove the migrated stent, with no complications. No significant bleeding or perforation developed after removal of the stent.

dominal pain. A simple abdominal radiograph showed that the metal stent had migrated from the ascending colon to the transverse colon ( $\bullet$ Fig. $\mathbf{1}$ ).

The colonoscopy revealed that the migrated uncovered stent was impacted and embedded within the bowel wall, in the transverse colon ( $\bullet$ Fig. $\mathbf{2 a}$ ). 
The patient's abdominal pain gradually worsened, so we attempted endoscopic stent retrieval. First, argon plasma coagulation (APC) (APC 300 and ICC 200; ERBE, Marietta, Georgia, USA) in forced mode was performed for ablation of the mucosa covering the stent ( $\nabla$ Fig. $\mathbf{2}$ b). The mean applied power output was $60 \mathrm{~W}$, and the gas flow rate ranged from 1.5 to $2.0 \mathrm{~L} / \mathrm{min}$. Coagulated necrotic tissue debris was created as a by-product of the APC procedure and was removed using forceps. APC was performed repeatedly on the remaining ingrown tissue. After detachment of a significant portion of the stent from the bowel wall, a detachable snare (MAJ 254; Olympus, Tokyo, Japan) was used to compress the distal part of the stent in order to avoid colonic mucosal injury due to the stent margin, which can occur during retrieval ( $\nabla$ Fig. 2c). However, after compressing the distal part of the stent, the proper muscle fibers of the colon and the stent wire were still attached via tight band-like tissue. Removing this tissue using APC could lead to deep muscle damage and delayed perforation due to transmural burn injury. Thus, dissection of the stent from the tightly attached tissue was carefully performed using the insulationtipped diathermic knife-2 set in drycut mode - effect 4 (ERBE IC200; ERBE, Tübin- gen, Germany) ( $\bullet$ Fig. 2 d). The stent was completely dissected and detached via this process. To retrieve the detached stent, a transparent cap (Olympus disposable distal attachment, D-201 - 14304) was attached to the colonoscope. The stent was compressed by the detachable snare, and the distal end of the stent was positioned completely within the transparent cap. Stent retrieval was performed very carefully to prevent bowel-wall injury by the distal edge of the stent wire. No significant bleeding or perforation developed after removal of the stent ( $\mathbf{F i g} \mathbf{2} \mathbf{e}$ ).

There have been no reports in the medical literature regarding endoscopic removal of SEMS trapped in the normal colon wall. This case is the first successful endoscopic retrieval of a SEMS trapped in the colon wall using APC, an insulation-tipped diathermic knife-2, and a detachable snare.

\section{Endoscopy_UCTN_Code_TTT_1AQ_2AF}

\section{Competing interests: None}

E. S. Kim, H. J. Chun, B. Keum, Y. S. Seo, Y. S. Kim, Y. T. Jeen, H. S. Lee, S. H. Um, C. D. Kim, H. S. Ryu

Department of Internal Medicine, Korea University College of Medicine, Seoul, Korea

\section{References}

1 Chun HJ, Kim ES, Hyun JJ et al. Gastrointestinal and biliary stents. J Gastroenterol Hepatol 2010; 25: 234-243

2 Small AJ, Coelho-Prabhu N, Baron TH. Endoscopic placement of self-expandable metal stents for malignant colonic obstruction: long-term outcomes and complication factors. Gastrointest Endosc 2010; 71: 560 572

3 Watt AM, Faragher IG, Griffin TT et al. Selfexpanding metallic stents for relieving malignant colorectal obstruction: a systematic review. Ann Surg 2007; 246: 24 - 30

Bibliography

DOI $10.1055 / \mathrm{s}-0030-1256205$

Endoscopy 2011; 43: E139-E140

(c) Georg Thieme Verlag KG Stuttgart · New York . ISSN 0013-726X

Corresponding author

H. J. Chun, MD, PhD

Department of Internal Medicine Korea University College of Medicine

126-1 Anam-dong 5-ga

Seongbuk-gu

Seoul 136-705

Korea

Fax: +82-2-9531943

drchunhj@chol.com 